\title{
A Cross-Sectional Study on Herpes Zoster Diagnosis in the Time of COVID-19
}

\author{
Niki Nourmohammadi MPH, ${ }^{1}$ Katerina Yale MD, ${ }^{2}$ Alessandro Ghigi MS, ${ }^{3}$ Kai Zheng PhD, ${ }^{3}$ \\ Natasha A. Mesinkovska MD, $\mathrm{PhD}^{2}$ \\ ${ }^{1}$ Lake Erie College of Osteopathic Medicine, Greensburg, PA, USA \\ ${ }^{2}$ University of California Irvine School of Medicine, Department of Dermatology, Irvine, USA \\ ${ }^{3}$ University of California Irvine Donald Bren School of Information and Computer Science, Department of \\ Informatics, Irvine, USA
}

\section{ABSTRACT}

Background: The COVID-19 pandemic has presented various cutaneous manifestations in COVID19 positive patients, including rising cases of herpes zoster $(\mathrm{HZ})$.

Objective: Our investigation sought to assess the proposed association between a positive COVID19 test result and herpes zoster, and determine whether the COVID-19 pandemic has affected the overall incidence of $\mathrm{HZ}$.

Methods: In this large cross- sectional study, patients were collected from University of California COVID Research Data Set (UC CORDS), a centralized, rapidly accumulating de-identified database and were then divided into those diagnosed with $\mathrm{HZ}$ before COVID test and those with $\mathrm{HZ}$ diagnosis after COVID testing. The total number of $\mathrm{HZ}$ cases to the total number of medical visits during the same six-month time frame (March to August) in 2019 and 2020 were also collected to assess if COVID-19 impacted the HZ incidence.

Results: A total of 608 patients were diagnosed with $\mathrm{HZ}$ from March 1 to August 31, 2020; of which, $2.1 \%(n=13)$ tested positive and $97.9 \%(n=595)$ tested negative for COVID-19. From March to August 2019 there were 4,349 reported $\mathrm{HZ}$ cases, and in comparison, there were 3,551 reported cases of $\mathrm{HZ}$ in 2020, a significant decrease $(x 2=90.6454, p<.00001)$.

Conclusion: There was no evidence to substantiate an association between $\mathrm{HZ}$ and COVID-19. The overall decrease in $\mathrm{HZ}$ incidence may be due to patients less likely to seek medical care.

\section{INTRODUCTION}

Amidst the COVID-19 pandemic, several published reports note concomitant cases of herpes zoster (HZ) infections in COVID-19 positive patients, suggesting a potential coexistence of the two viruses, or an increased incidence of $\mathrm{HZ}$ in this population (1-4). In order to investigate the credibility of this association and determine whether the COVID-19 pandemic has truly affected the overall incidence of $\mathrm{HZ}$, we analyzed the University of California COVID Research Data Set (UC CORDS).

This centralized, de-identified database provides access to health records for patients with COVID-19 PCR testing across November 2020 Volume 4 Issue 6 
five UC medical institutions: Davis, Irvine, Los Angeles, San Diego and San Francisco (5). From March 1 to August 31, 2020, it contains patient demographics, medical history, medical visit type (including inpatient, outpatient, and telehealth), and COVID-19 status on 226,093 patients. Patients collected from the UC CORDS were divided into two subgroups, those with a diagnosis code for $\mathrm{HZ}$ before COVID test and those with $\mathrm{HZ}$ after COVID testing within two months, prior or subsequent, of each other, to assess whether one infection may indicate the development of the other.

\section{METHODS}

To analyze whether there was an increase in the $\mathrm{HZ}$ condition rate during the pandemic, we compared the total number of $\mathrm{HZ}$ cases to the total number of medical visits during the same six-month time frame (March to August) in 2019 and 2020 using the general de-identified UC health data warehouse (UCHDW).

Statistical analysis was completed using chisquared tests to determine a significant relationship between those with or without $\mathrm{HZ}$ and COVID-19 infections.

\section{RESULTS}

To analyze whether there was an increase in the $\mathrm{HZ}$ condition rate during the pandemic, we compared the total number of $\mathrm{HZ}$ cases to the total number of medical visits during the same six-month time frame (March to August) in 2019 and 2020 using the general de-identified UC health data warehouse (UCHDW).

Statistical analysis was completed using chisquared tests to determine a significant relationship between those with or without $\mathrm{HZ}$ and COVID-19 infections.

A total of 608 patients were diagnosed with $\mathrm{HZ}$ from March 1 to August 31, 2020; of which, 2.1\% $(n=13)$ tested positive and 97.9\% ( $n=595)$ tested negative for COVID19 (Table 1). When compared to the overall COVID-19 positive test rate of $3.9 \%$ in the UC CORDS, the incidence of COVID-19 was lower in patients with $\mathrm{HZ}\left(X^{2}=4.9331\right.$, $\mathrm{p}=.0264$ ). Among patients with an $\mathrm{HZ}$ diagnosis prior to COVID-19 testing, only one patient $(0.3 \%)$ developed $\mathrm{HZ}$ within two months prior to COVID-19 diagnosis. Comparatively, among patients with a $\mathrm{HZ}$ diagnosis within two months subsequent to COVID-19 testing, only three patients (1.0\%) tested positive; one of which was diagnosed with $\mathrm{HZ}$ on the same day as COVID-19.

Table 1. Patients with Herpes Zoster Diagnosis who underwent COVID testing (UC CORDS) in March to August 2020

\begin{tabular}{|c|c|c|c|}
\hline $\begin{array}{l}\text { Condition (age } \\
\text { range, avg age) }\end{array}$ & $\begin{array}{c}\text { Total, } \\
\mathbf{n}\end{array}$ & $\begin{array}{c}\text { COVID-19 (+), } \\
\text { n (\%) }\end{array}$ & $\begin{array}{c}\text { COVID-19 (-) } \\
n\end{array}$ \\
\hline $\begin{array}{l}\text { HZ diagnosis } \\
\text { from March } 1 \text { to } \\
\text { August } 31,2020 \\
(8-89,59 \mathrm{v})\end{array}$ & 608 & $13(2.1 \%)$ & 595 \\
\hline Male & 248 & $2(0.8 \%)$ & 246 \\
\hline Female & 360 & $11(3.1 \%)$ & 349 \\
\hline $\begin{array}{l}\text { HZ diagnosis } \\
\text { within } 2 \text { months } \\
\text { prior to COVID- } \\
19 \text { test (11-89, } \\
60 y)\end{array}$ & 340 & $1(0.3 \%)$ & 339 \\
\hline Male & 138 & $0(0 \%)$ & 138 \\
\hline Female & 202 & $1(0.5 \%)$ & 201 \\
\hline $\begin{array}{l}\text { HZ diagnosis } \\
\text { within } 2 \text { months } \\
\text { after COVID-19 } \\
\text { test }(11-89,58 \mathrm{y})\end{array}$ & 297 & $3(1.0 \%)$ & 294 \\
\hline Male & 130 & $1(0.8 \%)$ & 129 \\
\hline Female & 167 & $2(1.2 \%)$ & 165 \\
\hline
\end{tabular}

Within the UCHDW, from March to August 2019 there were 4,349 reported HZ cases $(n=1,697,851)$, and in comparison, there were 3,551 reported cases of $\mathrm{HZ}$ in 2020 $(n=1,718,275) \quad$ (Table 2). These results November 2020 Volume 4 Issue 6 
demonstrate an $\mathrm{HZ}$ condition rate of 0.0026 in 2019 and 0.0021 in $2020\left(x^{2}=90.6454\right.$, $\mathrm{p}<.00001$ ), indicating a significant decrease.

Table 2. Cases of Herpes Zoster Recorded During COVID-19 Pandemic March-August 2019 vs. 2020 (De-Identified UCHDW)

\begin{tabular}{|ccc|}
\hline $\begin{array}{c}\text { Time Period } \\
\text { (avg age) } \\
\text { March- }\end{array}$ & $\begin{array}{c}\text { Herpes Zoster } \\
\text { cases, } \mathbf{n}\end{array}$ & $\begin{array}{c}\text { Condition } \\
\text { Rate }\end{array}$ \\
$\begin{array}{c}\text { August 2019 } \\
\text { (61y) } \\
\text { March- }\end{array}$ & 4349 & 0.0026 \\
$\begin{array}{c}\text { August 2020 } \\
\text { (60y) }\end{array}$ & 3551 & 0.0021 \\
\hline
\end{tabular}

\section{DISCUSSION}

In this study we did not find evidence to substantiate an association between $\mathrm{HZ}$ diagnosis and COVID-19. Additionally, the data suggests that, during the COVID-19 pandemic, there has been no increase in medical visits for $\mathrm{HZ}$ in the UC medical system, both in person and by telehealth. Limitations include use of tertiary center data, lack of clinical details, such as $\mathrm{HZ}$ location or disease treatment, due to deidentified data, rapidly changing testing criteria and availability, and inability for longitudinal follow-up. We recognize the overall number of $\mathrm{HZ}$ cases may be lower due to less patients seeking medical care due to the pandemic, leading to an apparent negative correlation between $\mathrm{HZ}$ and COVID-19. Future studies with larger databases may help better assess the details of this relationship.

\section{CONCLUSION}

In this limited dataset, there was no evidence to substantiate an association between $\mathrm{HZ}$ and COVID-19 infection, nor was there an increase in the number of cases of $\mathrm{HZ}$ during the time of the COVID19 pandemic.

Conflict of Interest Disclosures: The project described was supported by the National Center for Research Resources and the National Center for Advancing Translational Sciences, National Institutes of Health, through Grant UL1 TR001414. The content is solely the responsibility of the authors and does not necessarily represent the official views of the $\mathrm{NIH}$.

Funding: None

Corresponding Author:

Niki Nourmohammadi MPH

Lake Erie College of Osteopathic Medicine at Seton

Hill

20 Seton Hill Dr.

Greensburg, PA 15601

Phone: 949 903-3584

Email: NNourmoham98861@med.lecom.edu

\section{References:}

1. Tartari F, Spadotto A, Zengarini C, et al. Herpes zoster in COVID-19-positive patients. Int J Dermatol. 2020;59(8):1028-1029. doi:10.1111/ijd.15001

2. Shors AR. Herpes zoster and severe acute herpetic neuralgia as a complication of COVID-19 infection. JAAD Case Rep. 2020;6(7):656-657. doi:10.1016/j.jdcr.2020.05.012

3. Ertugrul G, Aktas H. Herpes zoster cases increased during COVID-19 outbreak. Is it possible a relation? [published online ahead of print, 2020 Jul 7]. J Dermatolog Treat. 2020;1. doi:10.1080/09546634.2020.1789040

4. de Freitas Ferreira ACA, Romão TT, Sllva Macedo Y, Pupe C, Nascimento OJ. COVID-19 and herpes zoster co-infection presenting with trigeminal neuropathy [published online ahead of print, 2020 May 24]. Eur J Neurol.

2020;10.1111/ene.14361. doi:10.1111/ene.14361

5. University of California. 2020. University Of California Health Creates Centralized Data Set To Accelerate COVID-19 Research. [online] Available at: $<$ https://www.universityofcalifornia.edu/pressroom/university-california-health-createscentralized-data-set-accelerate-covid-19research $>$ [Accessed 12 August 2020] 